\title{
The Qualitative and Quantitative Determination of the Phenolic Compounds in Polygonum Convolvulus L. Species, Polygonaceae Family
}

\author{
Olaru OT ${ }^{1}$, Anghel Adriana Iuliana ${ }^{1}$, Istudor Viorica ${ }^{2}$, Olaru Iulia loana ${ }^{3}$ \\ ${ }^{1}$ Department of Pharmaceutical Botany and Plant Cell Biology, Faculty of Pharmacy, "Carol Davila" University of Medicine and Pharmacy, Bucharest, Romania \\ 2 Department of Pharmacognosy, Phytochemistry and Phytotherapy, Faculty of Pharmacy, "Carol Davila" University of Medicine and Pharmacy, Bucharest, Romania \\ 3 SC Dexter Invest SRL, Bucharest, Romania
}

\begin{abstract}
Introduction: Polygonum convolvulus L. (black bindweed), syn. Fallopia convolvulus (L.) Á. Löve, Polygonaceae family is a plant from the spontaneous flora, spread from the plain zone up to the subalpine zone. The objectives of our researches are the qualitative and quantitative determination of polyphenolic compounds from Polygoni convolvuli herba and the choice of the adequate solvent for obtaining an active pharmacological extract.

Method: The qualitative exam consisted of phytochemical screening and thin layer chromatography. The quantitative determination of the total polyphenols was made through the Folin-Ciocâlteu method.

Results: The flavonoids, the anthocyanins, the tannins and the phenol carboxylic acids (phytochemical screening) were emphasized and the following compounds were identified: rutin, hyperoside, isoquercitroside, quercetin, myricetin, kaempferol and caffeic acid.

Conclusions: In order to establish the technological lab process for obtaining an active pharmacological extract standardized in total polyphenols the adequate solvent is ethanol $50 \%(\mathrm{v} / \mathrm{v})$.
\end{abstract}

Keywords: Fallopia convolvulus L., phenolic compounds, thin layer chromatography, spectrophotometric determination

Received: 3 May 2012

\section{Introduction}

Polygonum convolvulus L. (black bindweed), syn. Fallopia convolvulus (L.) Á. Löve, Polygonaceae family, is an annual, herbaceous plant, with voluble stem. The species is spread in Asia, Europe and acclimated in North America [1]. In our country the plant grows in different cultures and uncultivated areas, from plain up to the subalpine zone [2].

The specialized literature mentions the presence of the following phenolic compounds: flavonoids (heterosides of quercetin, myricetin, kaempferol, apigenin and luteolin) $[3,4]$, phenol carboxylic acids and their heterosides (3-OE-caffeoylquinic acid, 1-O-E-caffeoyl-beta-D-glucose, 3-O-E-p-coumaroyl-beta-D-glucose, caffeoyl tartaric acid and caffeoyl meso-tartaric acid) [5].

The objectives of this study consist of researching the phenolic compounds (flavones and phenol carboxylic acids) in Polygoni convolvuli herba and choosing the adequate solvent for obtaining an active pharmacological extract, in order to obtain a pharmaceutical product of phytotherapeutic use.

\section{Material and methods}

The plant material was harvested in Buftea, Ilfov department in July 2011. Its identity was established following a macroscopic and microscopic exam (on sections and pow-

Correspondence to: Octavian Olaru

E-mail: octav_olaru2002@yahoo.com ders examined with a Nikon Labophot 2 microscope), by comparing the morphological and anatomical characters with the ones described in literature $[1,2,4]$.

The qualitative exam was done according to the methods quoted by literature through chemical reactions characteristic to every class of active principles (phytochemical screening) [6] and thin layer chromatography (TLC).

Reference substances: caffeic acid, chlorogenic acid, dehydrated quercetin, kaempferol, miricetol $(3 \mathrm{mg} / \mathrm{mL})$ and rutin trihydrate, $(1 \mathrm{mg} / \mathrm{ml})$, hyperoside, isoquercitroside $(0.2 \mathrm{mg} / \mathrm{ml})$. The reference substances were rendered soluble in ethanol $96 \%$. All the reagents were of analytical purity (Sigma-Aldrich).

A. Preparation of the solutions to be analyzed: For the qualitative chemical exam and for the TLC: $2.5 \mathrm{~g}$ of vegetal product were refluxed for 30 minutes with $50 \mathrm{ml}$ of distilled water and with methanol $(\mathrm{m} / \mathrm{v})$. After cooling off they were filtered and completed up to $50 \mathrm{ml}$. The extractive solutions were codified PCA (the aqueous one) and PCM (the methanolic one). $12.5 \mathrm{ml}$ of the PCA and PCM solutions were subjected to the $\mathrm{HCl}$ hydrolysis, $1: 1(\mathrm{v} / \mathrm{v})$, then to the ethyl ether extraction (3 times with $10 \mathrm{ml}$ ). The combined ether solutions, dehydrated on anhydrous $\mathrm{Na}_{2} \mathrm{SO}_{4}$ and filtered were concentrated on the water bath, up to $5 \mathrm{ml}$. The respective solutions were marked as PCAH and $\mathrm{PCMH}$.

$B$. The TLC analysis developed as follows: the stationary phase - silica gel $60 \mathrm{~F}_{254}$ on an $\mathrm{Al}$ support; the mobile phase 

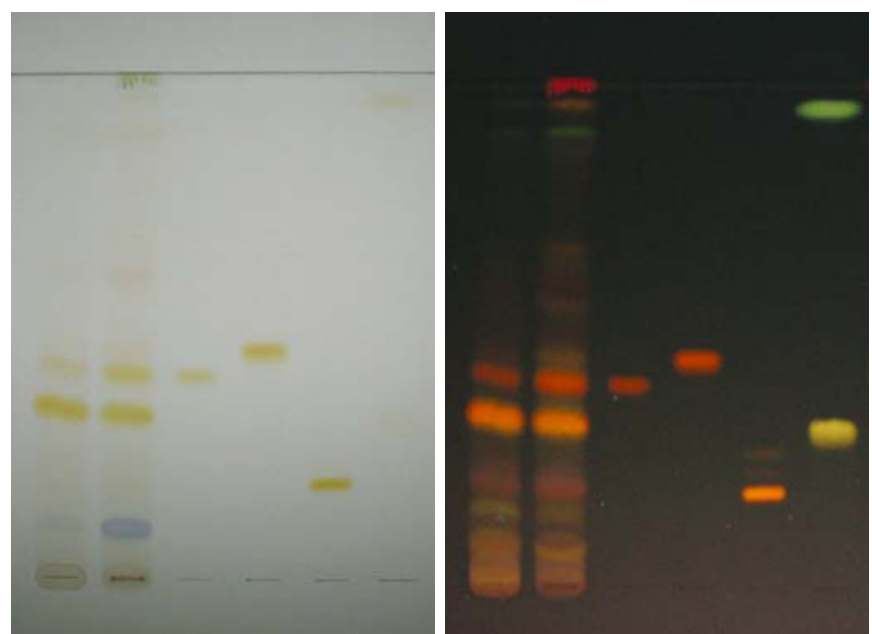

Fig. 1. The chromatograms with aqueous and methanolic solutions in Vis (A) and UV/366 nm (B): 1 - PCA, 2 - PCM, 3 - hyperoside, 4 - isoquercitrine, 5 - rutin, 6 - caffeic acid and chlorogenic acid (solvent 1 ).

- ethyl acetate:formic acid:acetic acid:water 72:7:7:14 (v/v/ $\mathrm{v} / \mathrm{v}$ ) (solvent 1 ) for the identification of the heterosides, and toluene:ethyl acetate:formic acid 5:3:1 ( $\mathrm{v} / \mathrm{v} / \mathrm{v})$ (solvent 2) for the identification of the aglycones; the reagents of revelation - Natural Reagent Product (diphenylboric acid amino ethyl ester $)=$ PEG (Neu/Peg. No.28). The examination of the strips was done visibly and UV-366 nm.

The solutions to be analyzed: PCA, PCM, PCAH and PCMH.

The order of applying the solutions to be analyzed and the reference substances on the chromatographic strips was as follows: 1 - PCA, 2 - PCM, 3 - hyperoside, 4 izoquercitrine, 5 - rutin, 6 - caffeic acid and chlorogenic acid (Figure 1A and 1B); 1 - PCAH, 2 - quercetol, 3 miricetol, 4 - kaempferol, 5 - caffeic acid (Figure 2A); 1 - PCMH, 2 - quercetol, 3 - miricetol, 4 - kaempferol, 5 - caffeic acid (Figure 2B).

C. Quantitative determination: In order to choose the solvent, the extraction method and the solvent/vegetal product connection we refluxed for 30 minutes $1 \mathrm{~g}$ of vegetal product with $50 \mathrm{ml}$ of solvent (water, ethanol $20 \%$, $50 \%, 80 \%)(\mathrm{v} / \mathrm{v})$. The extractive solutions were marked as $\mathrm{PC}_{\mathrm{H} 2 \mathrm{O}}, \mathrm{PC}_{\text {eth. } 20 \%}, \mathrm{PC}_{\text {eth. } 50 \%}$, and $\mathrm{PC}_{\text {eth. } 80 \%}$.

For the appreciation of the therapeutic activity we considered as sufficient the quantitative determination of the total phenolic compounds. This was done through the Folin-Ciocâlteu method modified by Gonzalez et al. [7] using a Memmert WNB 7-45 water bath and a UV-Vis Jasco V650 spectrophotometer. For expressing the results we chose as reference substance the chlorogenic acid (Sigma) $(0.01 \mathrm{mg} / \mathrm{mL}$ ethanol $50 \%)$, with which we first traced the calibration curve on the domain of concentrations $20-110 \mu \mathrm{g} / \mathrm{ml}$. From every extractive solution we made 5 dilutions. The resulting data were analyzed with the help of GraphPad Prism 5 and Microsoft Excel 2003 programs. The results are expressed in $\mathrm{g}$ of chlorogenic acid for $100 \mathrm{~g}$ of dried weight matter.
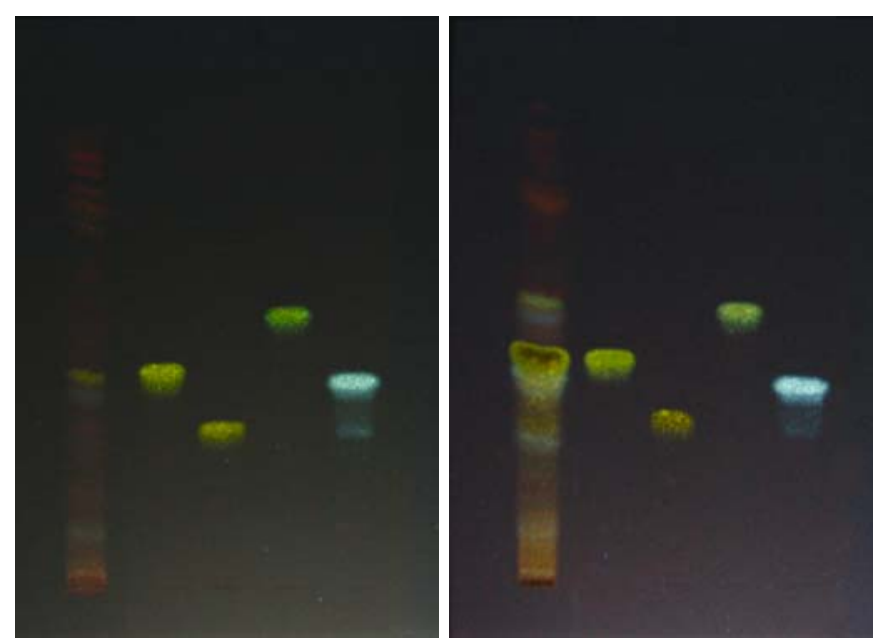

Fig. 2. The chromatograms with hydrolyzed solutions in UV/366 nm: 1 - PCAh (A), PCMh (B), 2 - quercetin (A and B), 3 - myricetin ( $A$ and $B$ ), $4-$ kaempferol ( $A$ and $B$ ), 5 - caffeic acid ( $A$ and $B$ ), solvent 2.

\section{Results}

A. The macro and microscopic characters coincide with the ones described in the literature (root and secondary structure stem, characteristic trichomes on the stem, leaf with an asymmetrical heterogenic structure).

Table I. The TLC results of the aqueous and methanolic solutions $-\mathrm{PC}_{\mathrm{A}}$ and $\mathrm{PC}_{\mathrm{M}}$ (solvent 1)

\begin{tabular}{|c|c|c|c|c|c|}
\hline \multirow{2}{*}{$\begin{array}{l}\text { Solution to } \\
\text { analyze }\end{array}$} & \multicolumn{2}{|c|}{ Vis } & \multicolumn{2}{|c|}{ UV/366 nm } & \multirow[t]{2}{*}{ Observations } \\
\hline & $\mathrm{Rf}$ & $\begin{array}{l}\text { Spot } \\
\text { color }\end{array}$ & $\mathrm{Rf}$ & $\begin{array}{c}\text { Spot } \\
\text { fluorescence }\end{array}$ & \\
\hline \multirow{10}{*}{$\mathrm{PC}_{\mathrm{A}}$} & - & - & 0.08 & orange & --- \\
\hline & 0.10 & purple & & & $\begin{array}{c}\text { possibly } \\
\text { anthocyanins }\end{array}$ \\
\hline & - & - & 0.15 & yellow-brown & --- \\
\hline & 0.20 & yellow & 0.20 & orange & rutin \\
\hline & 0.33 & yellow & 0.33 & yellow & --- \\
\hline & 0.41 & yellow & 0.41 & orange & hyperoside \\
\hline & 0.45 & yellow & 0.45 & orange & isoquercitrin \\
\hline & 0.60 & orange & - & - & --- \\
\hline & 0.86 & yellow & 0.86 & green & --- \\
\hline & 0.90 & yellow & 0.90 & green & caffeic acid \\
\hline \multirow{14}{*}{$\mathrm{PC}_{\mathrm{M}}$} & - & - & 0.07 & orange & --- \\
\hline & 0.09 & $\begin{array}{l}\text { purple- } \\
\text { blue }\end{array}$ & & & $\begin{array}{c}\text { possibly } \\
\text { anthocyanins }\end{array}$ \\
\hline & - & - & 0.14 & yellow-brown & --- \\
\hline & 0.18 & yellow & 0.18 & orange & rutin \\
\hline & 0.32 & yellow & 0.32 & yellow & --- \\
\hline & 0.40 & yellow & 0.40 & orange & hyperoside \\
\hline & 0.45 & yellow & 0.45 & orange & isoquercitrin \\
\hline & - & - & 0.56 & orange & --- \\
\hline & 0.60 & orange & 0.60 & red & --- \\
\hline & - & - & 0.65 & yellow & --- \\
\hline & 0.86 & yellow & 0.86 & green & --- \\
\hline & 0.90 & yellow & 0.90 & green & caffeic acid \\
\hline & - & - & 0.93 & orange & --- \\
\hline & 0.98 & green & 0.98 & red & chlorophyll \\
\hline
\end{tabular}

hyperoside $\mathrm{Rf}=0.40$ (vis-yellow, UV-orange), isoquercitrin $\mathrm{Rf}=0.45$ (vis-yellow, $\mathrm{UV}$ orange), rutin $\mathrm{Rf}=0.18$ (vis-yellow, UV-orange), chlorogenic acid $\mathrm{Rf}=0.30$ (vis-yellow, $\mathrm{UV}$-yellow), caffeic acid $\mathrm{Rf}=0.94$ (vis-yellow, UV-green) 
Table II. The TLC results of aqueous and methanolic solutions $\mathrm{PC}_{\mathrm{Ah}}$ and $\mathrm{PC}_{\mathrm{Mh}}$ (solvent 2)

\begin{tabular}{|c|c|c|c|}
\hline \multirow{2}{*}{$\begin{array}{l}\text { Solution to } \\
\text { analyze }\end{array}$} & \multicolumn{2}{|c|}{ UV/366 nm } & \multirow[t]{2}{*}{ Observations } \\
\hline & $\mathrm{Rf}$ & $\begin{array}{c}\text { Spot } \\
\text { fluorescence }\end{array}$ & \\
\hline \multirow{10}{*}{$\mathrm{PC}_{\mathrm{Ah}}$} & 0.03 & yellow & --- \\
\hline & 0.11 & blue & --- \\
\hline & 0.34 & red & --- \\
\hline & 0.41 & blue & caffeic acid \\
\hline & 0.45 & yellow & quercetin \\
\hline & 0.78 & yellow & --- \\
\hline & 0.82 & orange & --- \\
\hline & 0.86 & red & --- \\
\hline & 0.90 & red & --- \\
\hline & 0.93 & red & --- \\
\hline \multirow{12}{*}{$\mathrm{PC}_{\mathrm{Mh}}$} & 0.03 & yellow & --- \\
\hline & 0.29 & blue & --- \\
\hline & 0.32 & yellow & myricetin \\
\hline & 0.41 & blue & caffeic acid \\
\hline & 0.46 & yellow & quercetin \\
\hline & 0.51 & red & --- \\
\hline & 0.54 & blue & --- \\
\hline & 0.57 & green & kaempferol \\
\hline & 0.60 & red & --- \\
\hline & 0.78 & red & --- \\
\hline & 0.87 & red & --- \\
\hline & 0.92 & orange & --- \\
\hline
\end{tabular}

quercetin $\mathrm{Rf}=0.46$, myricetin $\mathrm{Rf}=0.33$, Kaempferol $\mathrm{Rf}=0.58 / 0.55$, caffeic acid $\mathrm{Rf}=0.44 / 0.40$

After the phytochemical screening, we identified, among the phenolic compounds, phenocarboxilic acids, flavonoids, anthocyanins and tannins.

B. Through TLC (Tables I, II and Figures 1, 2), according to the Rf values and to the behavior towards the reagents, identical to the reference substances, we identified: rutin, hyperoside, isoquercitroside and caffeic acid from $\mathrm{PC}_{\mathrm{A}}$ and $\mathrm{PC}_{\mathrm{M}}$ in solvent 1 , quercetin, kaempferol and myricetin - from the hydrolyzed solution, in solvent 2. The other spots remained unidentified due to the lack of the reference substances.

C. Results of the quantitative determinations (Table III)

The method is reproducible $(\mathrm{r} 2=0.9995 ; \mathrm{Y}=\mathrm{A} * \mathrm{X}+\mathrm{B}$, $\mathrm{A}=0.07534 \pm 0.0006088, \mathrm{~B}=0.05282 \pm 0.004326)$. The content of total polyphenols $/ 100 \mathrm{~g}$ of dried vegetal matter expressed in $\mathrm{g}$ of chlorogenic acid $(95 \% \mathrm{CI})$ is 4.208 5.082 for $\mathrm{PC}_{\mathrm{H} 2 \mathrm{O}}, 5.693-6.721$ for $\mathrm{PC}_{\text {eth.20\% }}, 6.903-7.429$ for $\mathrm{PC}_{\text {eth. } 50 \%}$ and $4.748-5.074$ for $\mathrm{PC}_{\text {eth. } 80 \%}$.

\section{Discussions}

The plant material that we analyzed contains flavonoids, phenol carboxylic acids, anthocyanins and tannins. The presence of caffeic acid, of some flavonoids (hytheroside, rutin and isoquercitrin) and of some flavonic aglycons (quercetin, kaempferol and myricetin) was confirmed through TLC.

Regarding the data in the specialized literature, in the product that we analyzed, we did not identify apigenin and luteolin in the hydrolyzed solutions, due to the lack of the respective reference substances.
Table III. The results of the quantitative analysis

\begin{tabular}{lccc}
\hline Solution to analyze & $\begin{array}{c}\text { average determination } \\
(\mathrm{g} \% \text { chlorogenic acid) }\end{array}$ & $\sigma$ & $\begin{array}{c}\text { Content of total } \\
\text { polyphenols } \\
(95 \% \mathrm{Cl})\end{array}$ \\
\hline $\mathrm{PC}_{\mathrm{H} 2 \mathrm{O}}$ & 4.645 & 0.218654 & $4.645 \pm 0.437$ \\
$\mathrm{PC}_{\text {eth. } 20 \%}$ & 6.207 & 0.257181 & $6.207 \pm 0.514$ \\
$\mathrm{PC}_{\text {eth. } 50 \%}$ & 7.166 & 0.131626 & $7.166 \pm 0.263$ \\
$\mathrm{PC}_{\text {eth. } 8 \%}$ & 4.911 & 0.081594 & $4.911 \pm 0.163$ \\
$\mathrm{PC}_{\text {eth. } 8 \%}$ & 4.911 & 0.081594 & $4.911 \pm 0.163$ \\
\hline
\end{tabular}

The blue-violet spot colors $(\mathrm{Rf}=0.1$, Vis $)$ probably correspond to some anthocyanins [8]. The chlorogenic acid could not be highlighted probably due to the superposition of the spots.

The content of total polyphenols is the following in ascending order: $\mathrm{PC}_{\mathrm{H} 2 \mathrm{O}}(4.645 \pm 0.437), \mathrm{PC}_{\text {eth. } 80 \%}(4.911$ $\pm 0.163), \mathrm{PC}_{\text {eth. } 20 \%}(6.207 \pm 0.514), \mathrm{PC}_{\text {eth. } 50 \%}$ (7.166 \pm 0.263). Because the lowest content of total polyphenols was obtained through extraction with water, and the highest through extraction with ethanol $50 \%$, we considered that this is the best solvent, among the tested ones, in order to obtain an active pharmacological extract standardized in total polyphenols. The methanol was excluded from the list of the tested solvents because of the toxicity.

\section{Conclusions}

The results of the research suggest that the Polygonum convolvulus $\mathrm{L}$. Species can be used as source of total polyphenols. In order to establish the technological lab process for obtaining an active pharmacological extract standardized in total polyphenols the adequate solvent is ethanol $50 \%$.

\section{Acknowledgement}

This paper is supported by the Sectoral Operational Programme Human Resources Development (SOP HRD), financed from the European Social Fund and by the Romanian Government under the contract number POSDRU/6/1.5/S/17.

\section{References}

1. Li A, Park C. Fallopia Adanson. In: Li A, Bao B, Grabovskaya-Borodina AE, Hong S, McNeill J, Mosyakin SL, Ohba H, Park C. Flora of China. 2003;5:315-318 (online source: http://efloras.org).

2. XXX Flora Republicii Populare Române. Ed. Academiei București, 1952, 1:476.

3. Kim MH, Park JH, Park CW. Flavonoid chemistry of Fallopia section Fallopia (Polygonaceae), Biochemical Systematics and Ecology. 2000;28:433-441.

4. Petrescu DA. Contribuții la studiul farmacognostic al speciei Polygonum convolvulus L., Teză de Doctorat, Institutul de Medicină și Farmacie, București, 1973, 13-15, 32-75.

5. Kjær C, Elmegaard N, Pedersen MB, Damgaard C, Nielsen JK Phytochemical responses to herbicide exposure and effects on herbivorous insects. Pesticides Research. 2001;55:20-25.

6. Gîrd CE, Duțu LE, Popescu ML, Pavel M, Tudor I, lordache AT. Bazele teoretice și practice ale analizei farmacognostice, Ed. Curtea Veche, București, 2008, 1:104-106, 136, 152-153, 169.

7. González M, Guzmán B, Rudyk R, Romano E, Molina MAA. Spectrophotometric Determination of Phenolic Compounds in Propolis, Lat. Am. J. Pharm. 2003;22(3):243-248.

8. Wagner H, Bladt S. Plant Drug Analysis: A Thin Layer Chromatography Atlas, 2nd edition. Springer-Verlag, Berlin, 1996, 197, 286-288. 